\title{
Optimasi Cluster Pada Data Stunting: Teknik Evaluasi Cluster Sum of Square Error dan Davies Bouldin Index
}

\author{
Deny Jollyta ${ }^{1}$, Syahril Efendi' ${ }^{2}$, Muhammad Zarlis ${ }^{2}$, Herman Mawengkang ${ }^{3}$ \\ ${ }^{1}$ Program Doktoral Ilmu Komputer dan Teknologi Informasi, Universitas Sumatera Utara \\ ${ }^{2}$ Fakultas Ilmu Komputer dan Teknologi Informasi, Universitas Sumatera Utara \\ ${ }^{3}$ Fakultas Matematika, Universitas Sumatera Utara \\ Jl. Universitas No. 9A Kampus USU, Medan \\ deny.jollyta@students.usu.ac.id
}

\begin{abstract}
The clusters number optimization problem is a problem that still requires continuous research so that the information produced can be a consideration. Cluster evaluation techniques with Sum of Square Error (SSE) and Davies Bouldin Index (DBI) are techniques that can evaluate the number of clusters from a data test. Research with these two techniques utilizes Stunting data from a number of regions in Indonesia. The result is information on stunting data which is formed from the optimal number of clusters where the largest SSE is formed at $k=5$ and the smallest DBI is formed at $k=5$, with values of 23.403 and 1,178 respectively. Changes in the number of clusters also influence the information produced and DBI is proven to produce optimal number of clusters that contain information with a better pattern because it has a small intra-cluster value. It is expected that the results of this study can show the performance of the two evaluation techniques in producing the optimal number of clusters so that grouping information is in accordance with the expected pattern.
\end{abstract}

Keywords: Cluster, Optimization, SSE, DBI

Abstrak-Permasalahan optimasi jumlah cluster merupakan masalah yang masih membutuhkan penelitian berkelanjutan agar informasi yang dihasilkan dapat menjadi pertimbangan. Teknik evaluasi cluster dengan Sum of Square Error (SSE) dan Davies Bouldin Index (DBI) merupakan teknik yang dapat melakukan evaluasi terhadap jumlah cluster dari sebuah pengujian data. Penelitian dengan kedua teknik ini memanfaatkan data Stunting dari sejumlah wilayah di Indonesia. Hasilnya merupakan informasi data stunting yang terbentuk dari jumlah cluster optimal dimana SSE terbesar dibentuk pada $k=5$ dan DBI terkecil dibentuk pada $k=5$ dengan nilai masing-masing adalah 23.403 dan 1.178. Perubahan jumlah cluster turut mempengaruhi informasi yang dihasilkan dan DBI terbukti menghasilkan jumlah cluster optimal yang berisikan informasi dengan pola yang lebih baik karena memiliki nilai intra cluster kecil. Diharapkan hasil penelitian ini dapat memperlihatkan kinerja kedua teknik evaluasi dalam menghasilkan jumlah cluster optimal sehingga informasi pengelompokan sesuai dengan pola yang diharapkan.

Kata kunci: Cluster, Optimasi, SSE, DBI

\section{PENDAHULUAN}

Mining adalah penambangan yang mencirikan proses dalam menemukan informasi berharga dalam database yang sangat besar [1]. Berbagai metode dalam data mining digunakan untuk menganalisa data demi mendapatkan informasi berharga. Clustering merupakan salah satu cara untuk menganalisa data melalui 
pengelompokan objek data yang mirip satu sama lain dalam cluster yang sama dan berbeda dengan objek di cluster lain [1]. Salah satu metode clustering yang terkenal adalah K-Means. Permasalahan yang sering terjadi pada clustering yang menggunakan K-Means adalah belum adanya ketentuan jumlah cluster yang tepat dari sejumlah $\mathrm{k}$ yang diujikan pada data. Tidak ada ukuran terbaik untuk pengelompokan data [1]. Hal ini menyebabkan informasi dari pengelompokan terkadang tidak sesuai dengan pola yang ada atau yang diharapkan. Saat ini telah banyak metode atau algoritma yang dihasilkan untuk menentukan jumlah cluster terbaik. Berbagai metode seperti Elbow, Dynamic Cluster Algorithm, Hamming Distance dan Xie Beni Index, merupakan cara yang ditemukan untuk menghasilkan jumlah cluster yang optimal. Metode-metode tersebut tidak berdiri sendiri dalam menentukan jumlah cluster yang tepat. Terdapat pula teknik untuk mengevaluasi cluster yang dihasilkan berdasarkan error tertinggi dan index terkecil yang dihasilkan, seperti Sum of Square Error (SSE) dan Davies Bouldin Index (DBI). Kedua teknik ini sangat membantu dalam memastikan jumlah cluster yang paling optimal dari sejumlah k yang diujikan pada data.

Pada penelitian [2], SSE menghasilkan jarak terbesar dari sejumlah pengujian k sesuai dengan konsep metode Elbow yang diterapkan pada pengelompokan konsumen terbaik menggunakan K-Means. Dalam [3], SSE melakukan optimasi jumlah cluster pada klasterisasi energi WSN. Pengujian dilakukan menggunakan aplikasi Matlab dengan beberapa variasi parameter performance yang ada pada Matlab untuk memperoleh jumlah cluster yang optimal. Selain itu evaluasi cluster menggunakan SSE dan metode Elbow, juga dikolaborasikan dengan Adjusted Rand Index (ARI) dan Silhouette Coefficient untuk menemukan cluster paling optimal melalui pengujian yang dilakukan dengan metode Ek-NNclus [4]. DBI merupakan teknik evaluasi cluster yang digunakan pada segmentasi nasabah potensial hasil pengujian algoritma K-Means [5]. DBI diperlukan untuk menyempurnakan kinerja sebuah metode atau algoritma optimasi demi mendapatkan jumlah cluster yang terbaik. Pada penelitian [6], DBI digunakan untuk seleksi atribut berdasarkan koefisien variansi dan korelasi pada pemetaan e-government tahun 2016. DBI dikombinasikan dengan algoritma erisoglu, calis, dan sakallioglu untuk meningkatkan kinerja dalam menghasilkan cluster terbaik. DBI juga berhasil menentukan jumlah cluster optimal dalam melacak target dengan celerity variable yang tinggi [7]. Pada penelitian yang dibantu dengan aplikasi RapidMiner ini bertujuan untuk menghasilkan jumlah cluster yang optimal melalui komparasi performa teknik evaluasi cluster SSE dan DBI. Performa SSE dan DBI juga diuraikan dalam bentuk informasi yang dihasilkan dari setiap cluster dari k yang paling baik sehingga diharapkan informasi tersebut dapat menjadi acuan kebijakan karena sudah terpola dan sesuai dengan yang diharapkan.

\section{MATERIAL DAN METODOLOGI PENELITIAN}

\subsection{Metode Elbow dan Sum of Square Error (SSE)}

Metode Elbow bekerja membandingkan nilai atau persentase dari sejumlah $\mathrm{k}$ yang telah diujikan dan membentuk siku pada suatu titik [3]. Nilai $\mathrm{k}$ pada kombinasi siku dengan $K$-Means adalah grafik hubungan cluster dengan penurunan error. Peningkatan nilai k menyebabkan grafik menurun perlahan sampai hasil 
nilai k stabil [2]. Jumlah cluster k yang dihasilkan dari pengujian dengan K-Means, dievaluasi menggunakan teknik SSE. Semakin banyak jumlah k yang diujian, maka nilai SSE semakin kecil [8]. SSE merupakan cara dalam melakukan validasi cluster melalui jumlah kuadrat setiap anggota cluster menuju pusatnya [9]. Semakin jauh jarak yang membentuk titik siku, maka jumlah cluster tersebut menjadi yang paling optimal. Rumus SSE adalah sebagai berikut [10]:

$$
S S E=\sum_{K=1}^{K} \sum_{x_{i} S_{K}}\left\|x_{i}-c_{k}\right\|_{2}^{2}
$$

\subsection{Davies Bouldin Index (DBI)}

Metode DBI ini pertama kali diusulkan oleh David L. Davies dan Donald W.Bouldin pada tahun 1979. Evaluasi menggunakan DBI ini memiliki skema evaluasi cluster internal, dimana baik atau tidaknya hasil cluster dilihat dari kuantitas dan kedekatan antar data hasil cluster. Dalam penelitian [5], dijelaskan bahwa $D B I$ adalah fungsi rasio dari jumlah antara cluster scatter sampai dengan cluster separation. Pendekatan pengukuran DBI yaitu memaksimalkan jarak inter cluster serta meminimalkan jarak intra cluster. Semakin kecil nilai DBI menunjukan skema cluster yang paling optimal [5]. Rumus DBI adalah [11]:

$$
\begin{aligned}
& R_{j, k}=\frac{M A E_{j}+M A E_{k}}{d\left(c_{j}, c_{k}\right)} \\
& D B I=\frac{1}{M} \sum_{j=1}^{M} \max _{j \neq k} R_{j, k}
\end{aligned}
$$

\subsection{Kerangka Kerja Penelitian}

Untuk mendapatkan hasil pengelompokan dengan nilai $\mathrm{k}$ yang optimal, dilakukan dengan beberapa tahapan seperti yang ditampilkan pada Gambar 1.

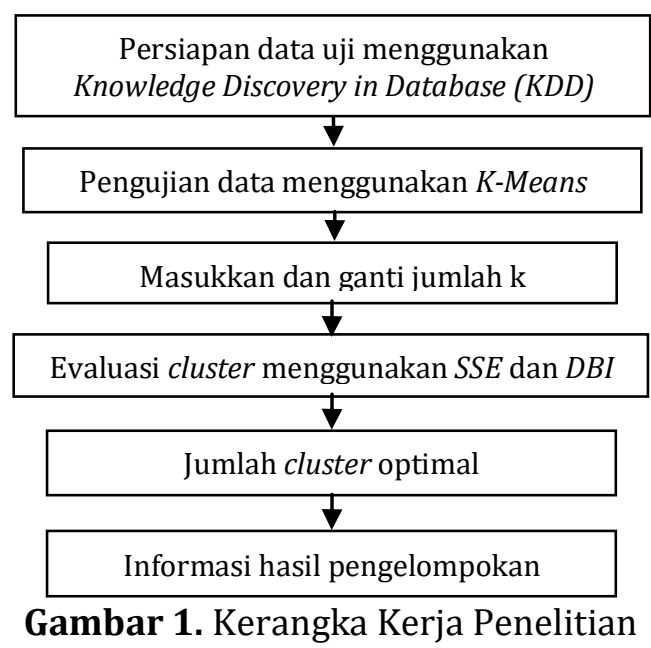

Penelitian diawali dengan mempersiapkan data pengujian yakni data Stunting. Persiapan data mengikuti langkah yang terdapat dalam Knowledge 
Discovery in Database (KDD), dimulai dengan seleksi data, pemilihan data dan transformasi data, hingga data siap untuk diujikan.

Atribut-atribut tersebut dipilih untuk mendapatkan informasi berdasarkan pengelompokan yang terbentuk setelah proses pengujian selesai dilakukan. Data diujikan dengan algoritma $K$-Means dengan memasukkan sejumlah k, mulai dari $\mathrm{k}=3$ hingga $\mathrm{k}=10$ dengan jumlah data 150 . Hasil pengujian berupa nilai dari beberapa jumlah $\mathrm{k}$ yang selanjutnya dievaluasi menggunakan teknik evaluasi cluster SSE dan DBI. Hasil evaluasi SSE dan DBI merupakan jumlah cluster yang paling optimal dari pengelompokan yang terbentuk.

\subsection{Data Uji}

Stunting merupakan masalah gizi kronis pada balita yang ditandai dengan tinggi badan yang lebih pendek dari anak seusianya [12]. Istilah Stunting sangat lekat dengan sebutan kerdil bagi anak yang tumbuh dengan kurang sempurna. Kondisi Stunting disebabkan oleh beberapa atribut yakni kondisi calon ibu, usia, jarak kehamilan, postur calon ibu, kondisi ekonomi, kondisi sosial, gizi bayi dan kesakitan pada bayi [12]. Data disusun berdasarkan atribut-atribut tersebut untuk dikelompokkan. Informasi terkait kondisi bayi atau anak yang stunting dapat terbentuk sesuai kondisi yang ada agar informasi yang diperoleh dapat dipertanggungjawabkan. Deskripsi data yang diujikan dapat dilihat pada Tabel 1.

Tabel 1. Deskripsi Atribut Data Stunting Wilayah Indonesia

\begin{tabular}{|c|c|c|}
\hline No & Atribut & Deskripsi Atribut \\
\hline 1 & $\begin{array}{l}\text { Kondisi } \\
\text { calon ibu }\end{array}$ & $\begin{array}{l}\text { Terdiri dari kecukupan gizi calon ibu, postur calon ibu, jarak kehamilan, } \\
\text { usia }\end{array}$ \\
\hline 2 & Usia & Terdiri dari usia terlalu tua, terlalu muda dan cukup umur \\
\hline 3 & $\begin{array}{l}\text { Jarak } \\
\text { kehamilan }\end{array}$ & $\begin{array}{l}\text { Terdiri dari calon ibu yang setiap tahun melahirkan dan calon ibu yang } \\
\text { melahirkan dengan jarak antar kelahiran } 2 \text { tahun atau lebih }\end{array}$ \\
\hline 4 & $\begin{array}{l}\text { Postur } \\
\text { calon ibu }\end{array}$ & Terdiri dari tinggi badan calon ibu yang ideal dan pendek \\
\hline 5 & $\begin{array}{l}\text { Kondisi } \\
\text { ekonomi }\end{array}$ & Terdiri dari keadaan tidak mampu, cukup dan ideal \\
\hline 6 & $\begin{array}{l}\text { Kondisi } \\
\text { social }\end{array}$ & Terdiri dari keadaan sanitasi dan keamanan pangan \\
\hline 7 & Gizi Bayi & $\begin{array}{l}\text { Terdiri dari inisiasi menyusui dini (IMD), gagal ASI ekslusif, penyapihan } \\
\text { dini dan makanan pendamping ASI (MP-ASI) }\end{array}$ \\
\hline 8 & $\begin{array}{l}\text { Kesakitan } \\
\text { pada bayi }\end{array}$ & Terdiri dari gangguan kognitif, motorik dan gangguan verbal \\
\hline
\end{tabular}

Sumber: (Buletin Stunting, 2018)

Kedelapan atribut data pada Tabel 1 merupakan deskripsi dari data yang dikelompokkan menggunakan algoritma K-Means dan dipersiapkan melalui tahapan $K D D$ untuk selanjutnya dievaluasi jumlah cluster yang terbentuk dengan SSE dan DBI.

\section{HASIL DAN PEMBAHASAN 3.1 Hasil Pengelompokan}


Data Stunting diujikan melalui algoritma K-Means dengan jumlah cluster uji mulai dari $\mathrm{k}=3$ hingga $\mathrm{k}=10$ menggunakan aplikasi RapidMiner. Hasil pengujian pertama merupakan hasil uji yang menggunakan evaluasi cluster SSE dengan parameter similarity dan performance dalam aplikasi RapidMiner. Jumlah anggota tiap pengelompokan ditampilkan pada Tabel 2 berikut.

Tabel 2. Pengelompokan dengan Evaluasi SSE

\begin{tabular}{|l|l|l|}
\hline Jumlah k & $\begin{array}{l}\text { Jarak antar } \\
\text { Cluster }\end{array}$ & Jumlah Anggota Cluster \\
\hline 3 & 88.963 & cluster_2 (64), cluster_1 (34), cluster_0 (52) \\
\hline 4 & 59.995 & cluster_2 (50), cluster_3 23), cluster_1 (31), cluster_0 (46) \\
\hline 5 & 54.43 & $\begin{array}{l}\text { cluster_0 (50), cluster_3 (24), cluster_2 (25), cluster_4 (45), } \\
\text { cluster_1 (6) }\end{array}$ \\
\hline 6 & 39.178 & $\begin{array}{l}\text { cluster_5 (39), cluster_0 (22), cluster_3 (25), cluster_2 (39), } \\
\text { cluster_1 (19), cluster_4 (6) }\end{array}$ \\
\hline 7 & 36.978 & $\begin{array}{l}\text { cluster_0 (37), cluster_2 (23), cluster_1 (23), cluster_6 (20), } \\
\text { cluster_5 (39), cluster_4 (6), cluster_3 2) }\end{array}$ \\
\hline 8 & 29.907 & $\begin{array}{l}\text { cluster_7 (15), cluster_6 (22), cluster_1 (23), cluster_0 (30), } \\
\text { cluster_2 (17), cluster_4 (6), cluster_5 (35), cluster_3 (2) }\end{array}$ \\
\hline 9 & 29.261 & $\begin{array}{l}\text { cluster_0 (15), cluster4 (21), cluster_1 (23), cluster_8 (19), } \\
\text { cluster_7 (39), cluster_3 (4), cluster_6 (24), cluster_2 (2), } \\
\text { cluster_5 (3) }\end{array}$ \\
\hline 10 & 22.771 & $\begin{array}{l}\text { cluster_7 (20), cluster_2 (21), cluster_0 (23), cluster_4 (17), } \\
\text { cluster_5 (28), cluster_6 (3), cluster_9 (12), cluster_3 (2), } \\
\text { cluster_8 (20), cluster_1 (4) }\end{array}$ \\
\hline
\end{tabular}

Jarak antar anggota cluster dari setiap pengujian $\mathrm{k}$ membentuk jumlah anggota dalam setiap kelompok yang terbentuk. Semakin banyak jumlah k yang diujikan, maka jarak antar cluster semakin kecil.

Selanjutnya hasil pengujian ditampilkan untuk penggujian yang dievaluasi dengan DBI. Parameter RapidMiner yang digunakan untuk menghasilkan pengelompokan ini adalah cluster distance performance. Jumlah anggota tiap pengelompokan ditampilkan pada Tabel 3 berikut.

Tabel 3. Pengelompokan dengan Evaluasi $D B I$

\begin{tabular}{|c|c|c|}
\hline $\begin{array}{l}\text { Jumlah } \\
\text { k }\end{array}$ & $\begin{array}{l}\text { Jarak antar } \\
\text { Cluster }\end{array}$ & Jumlah Anggota Cluster \\
\hline 3 & 1.622 & cluster_1 (61), cluster_o (50), cluster_2 (39) \\
\hline 4 & 1.336 & cluster_2 (49), cluster_1 (24), cluster_o (31), cluster_3 (46) \\
\hline 5 & 1.206 & $\begin{array}{l}\text { cluster_1 (50), cluster_4 (23), cluster_3 (25), cluster_2 (42), } \\
\text { cluster_0 (10) }\end{array}$ \\
\hline 6 & 1.071 & $\begin{array}{l}\text { lluster_4 (50), cluster_0 (22), cluster_3 (25), cluster_5 (19), } \\
\text { cluster_1 (28), cluster_2 (6) }\end{array}$ \\
\hline 7 & 1.003 & $\begin{array}{l}\text { cluster_6 (30), cluster_0 (22), cluster_5 (25), cluster_2 (12), } \\
\text { cluster_3 }(11), \text { cluster_4 }(44), \text { cluster_1 (6) }\end{array}$ \\
\hline 8 & 0.925 & $\begin{array}{l}\text { cluster_3 (15), cluster_6 (21), cluster_1 (25), cluster_5 (28), } \\
\text { cluster_2 (18), cluster_7 }(6), \text { cluster_4 (18), cluster_o (19) }\end{array}$ \\
\hline 9 & 0.909 & 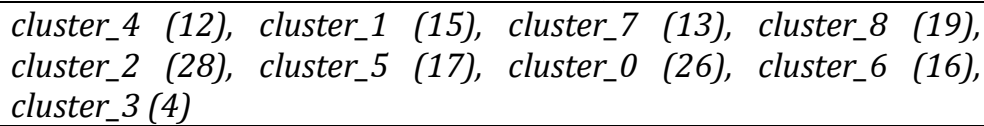 \\
\hline 10 & 0.836 & cluster_0 (18), cluster_2 (22), cluster_8 (8), cluster_6 (10), cluster_3 \\
\hline
\end{tabular}




\begin{tabular}{|l|l|l|}
\hline $\begin{array}{l}\text { Jumlah } \\
\mathbf{k}\end{array}$ & $\begin{array}{l}\text { Jarak antar } \\
\text { Cluster }\end{array}$ & \begin{tabular}{l} 
Jumlah Anggota Cluster \\
\hline
\end{tabular} \\
$\begin{array}{l}\text { (11), cluster_5 (12), cluster_9 (6), cluster_4 (17), cluster_7 (17), } \\
\text { cluster_1 (29) }\end{array}$ \\
\hline
\end{tabular}

Nilai jarak yang terbentuk dari hasil pengelompokan menggunakan parameter DBI pada Tabel 3 jauh lebih kecil, baik dari jarak antar cluster maupun jarak antar anggota cluster. Hasil perhitungan jarak membentuk keanggotaan yang hampir merata di setiap cluster. Hal ini menunjukkan bahwa kemiripan setiap anggota cluster sangat kuat sehingga membentuk informasi yang sesuai dengan keadaan yang ada.

\subsection{Evaluasi Cluster SSE dan DBI untuk Penentuan Cluster Optimal}

Penelitian ini menggunakan 8 kali perubahan jumlah cluster. Untuk menentukan jumlah cluster yang paling optimal, dilakukan evaluasi cluster dengan Sum of Square Error (SSE) dan Davies Bouldin Index (DBI). Setiap pengujian menghasilkan nilai jarak yang saling dibandingkan sesuai ketentuan. Adapun nilai kedua teknik evaluasi ditampilkan oleh Tabel 4.

Tabel 4. Nilai Evaluasi Cluster SSE dan DBI

\begin{tabular}{|l|l|l|}
\hline Jumlah k & Nilai $S S E$ & Nilai $D B I$ \\
\hline $\mathrm{k}=3$ & Inisiasi & 1.196 \\
\hline $\mathrm{k}=4$ & 28.968 & 1.185 \\
\hline $\mathbf{k}=\mathbf{5}$ & 5.565 & 1.178 \\
\hline $\mathrm{k}=6$ & 15.252 & 1.265 \\
\hline $\mathrm{k}=7$ & 2.2 & 1.292 \\
\hline $\mathrm{k}=8$ & 7.071 & 1.305 \\
\hline $\mathrm{k}=9$ & 0.646 & 1.365 \\
\hline $\mathrm{k}=10$ & 6.49 & 1.387 \\
\hline
\end{tabular}

Nilai SSE didasarkan pada besarnya error yang dihasilkan untuk dapat membentuk siku dan menjadi jarak terbesar. Pada Tabel 4, jarak terbesar terdapat pada k = 5. Grafik hasil perhitungan SSE dapat dilihat pada Gambar 2.

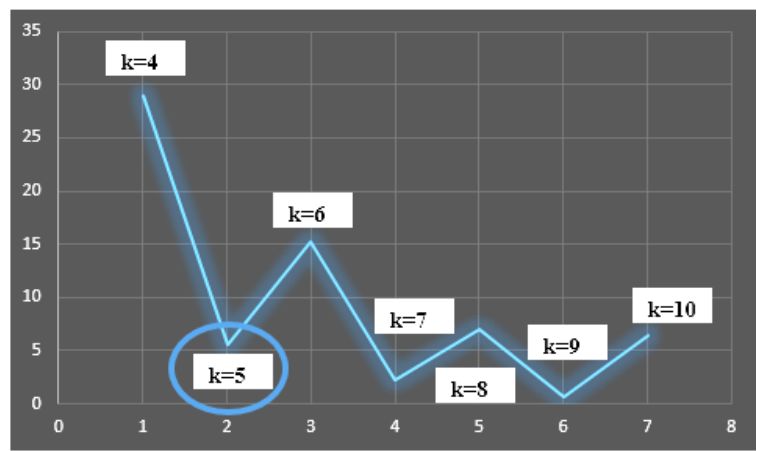

Gambar 2. Cluster Optimal Teknik SSE

Sedangkan untuk teknik $D B I$, semakin kecil nilai indek yang terbentuk, semakin optimal cluster tersebut. $D B I$ terkecil juga terdapat pada $\mathrm{k}=5$. Grafik $D B I$ dapat ditampilkan seperti pada Gambar 3. 


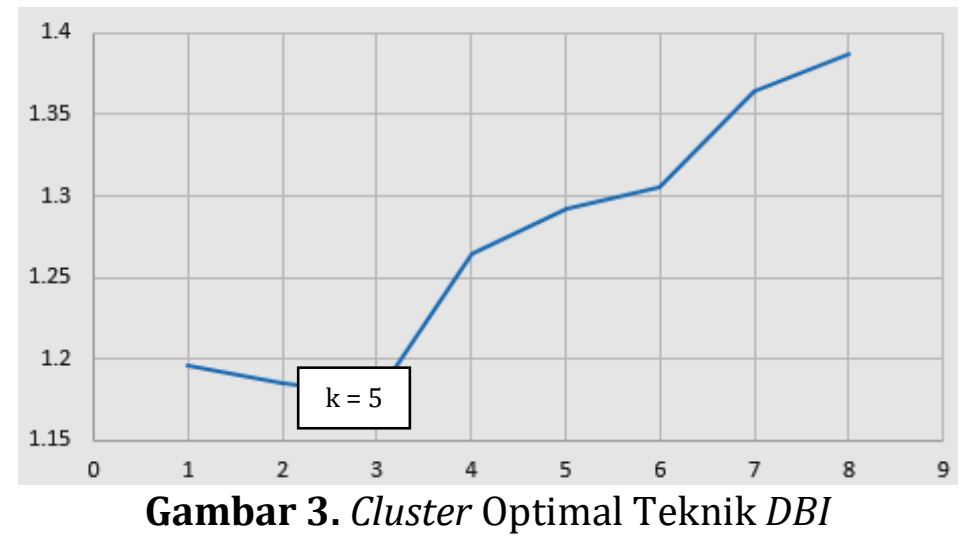

Pengujian data Stunting menghasilkan jumlah cluster optimal yang sama melalui teknik evaluasi $S S E$ dan $D B I$. Pada $\mathrm{k}=5$, perhitungan $S S E$ dan $D B I$ sampai pada perhitungan cluster yang paling baik. Namun demikian, walau cluster optimal sama-sama berada pada $\mathrm{k}=5$, informasi yang terbentuk berbeda. Hal ini terlihat dari keanggotaan tiap cluster yang tidak sama, yang artinya adalah informasi atau pengetahuan yang dapat dijadikan acuan juga menjadi tidak sama. Tabel 5 berikut merupakan informasi dari masing-masing evaluasi cluster SSE dan DBI pada $\mathrm{k}=5$.

Tabel 5. Informasi Hasil Pengelompokan K-Means Pada k=5

\begin{tabular}{|c|c|c|c|}
\hline $\begin{array}{l}\text { Jumlah } \\
\text { k (SSE) }\end{array}$ & Informasi & $\begin{array}{l}\text { Jumlah } \\
\text { k (DBI) }\end{array}$ & Informasi \\
\hline 0 & $\begin{array}{l}\text { Cluster ini berisikan } 50 \\
\text { anggota yang menunjukkan } \\
\text { bahwa bayi stunting lebih } \\
\text { disebabkan oleh kondisi } \\
\text { ekonomi yang parah. } \\
\text { Akibatnya calon ibu kurang } \\
\text { gizi, pertumbuhan tidak ideal } \\
\text { dan tidak } \\
\text { menghasilkan ASI mampu }\end{array}$ & 1 & $\begin{array}{l}\text { Merupakan kelompok bayi } \\
\text { stunting yang berjumlah } 50 \text { dari } \\
\text { calon ibu ekonomi bawah, kurang } \\
\text { gizi, berpostur pendek dan } \\
\text { lingkungan yang kurang sanitasi. } \\
\text { Akibatnya calon ibu tidak mampu } \\
\text { memproduksi ASI sehingga bayi } \\
\text { juga ada yang mengalami } \\
\text { gangguan motorik, kognitif dan } \\
\text { verbal }\end{array}$ \\
\hline 3 & $\begin{array}{l}\text { Anggota cluster yang } \\
\text { berjumlah } 24 \text { anggota ini } \\
\text { memberikan informasi bahwa } \\
\text { bayi stunting berasal dari calon } \\
\text { ibu ekonomi menengah namun } \\
\text { gagal ASI. Calon ibu juga sudah } \\
\text { terlalu tua untuk melahirkan } \\
\text { dan memiliki riwayat } \\
\text { kehamilan yang berdekatan } \\
\text { sehingga selain stunting, bayi } \\
\text { juga mengalami gangguan } \\
\text { motorik }\end{array}$ & 4 & $\begin{array}{l}\text { Cluster ini memiliki } 23 \text { bayi } \\
\text { stunting yang berasal dari } \\
\text { keluarga mampu. Namun calon ibu } \\
\text { memiliki postur yang pendek dan } \\
\text { gagal ASI. Akibatnya bayi } \\
\text { mengalami gangguan motorik dan } \\
\text { kognitif yang semakin } \\
\text { menghambat pertumbuhannya }\end{array}$ \\
\hline 2 & $\begin{array}{l}\text { Informasi dari kelompok } \\
\text { dengan } 25 \text { anggota ini adalah } \\
\text { bahwa gangguan motorik pada } \\
\text { bayi stunting juga dapat } \\
\text { dialami oleh calon ibu yang }\end{array}$ & 3 & $\begin{array}{l}\text { Ke-25 bayi dalam cluster ini } \\
\text { sebagian besar menggalami } \\
\text { gangguan motorik. Walaupun } \\
\text { calon ibu berasal dari keluar } \\
\text { menengah ke atas, namun postur }\end{array}$ \\
\hline
\end{tabular}




\begin{tabular}{|c|c|c|c|}
\hline $\begin{array}{l}\text { Jumlah } \\
\text { (SSE) }\end{array}$ & Informasi & $\begin{array}{l}\text { Jumlah } \\
\text { k DDBI }\end{array}$ & Informasi \\
\hline & $\begin{array}{l}\text { berpostur pendek dengan } \\
\text { riwayat ekonomi dan sosial } \\
\text { yang cukup }\end{array}$ & & $\begin{array}{l}\text { tubuh calon ibu yang pendek turut } \\
\text { menentukan pembentukan bayi } \\
\text { stunting }\end{array}$ \\
\hline 4 & $\begin{array}{l}45 \text { anggota cluster ini adalah } \\
\text { bayi stunting yang dilahirkan } \\
\text { dari ibu belum cukup umur, } \\
\text { berekonomi-sosial menengah } \\
\text { ke bawah, dan gagal ASI. Selain } \\
\text { stunting, } 42 \% \text { bayi pada cluster } \\
\text { ini mengalami gangguan } \\
\text { kognitif, } 47 \% \quad \text { gangguan } \\
\text { motorik dan sisanya } \\
\text { mengalami gangguan verbal }\end{array}$ & 2 & $\begin{array}{l}\text { Cluster ini berisikan } 42 \text { bayi } \\
\text { stunting yang dilahirkan oleh } \\
\text { calon ibu dengan usia masih } \\
\text { sangat muda, kondisi ekonomi } \\
\text { sosial yang sangat tidak memadai, } \\
\text { postur tubuh pendek dan riwayat } \\
\text { kehamilan yang rapat. Kekurangan } \\
\text { gizi dan gagal ASI mengakibatkan } \\
\text { bayi mengalami gangguan } \\
\text { motorik, kognitif dan verbal }\end{array}$ \\
\hline 1 & $\begin{array}{l}\text { Cluster yang beranggotakan } 6 \\
\text { bayi stunting ini dilahirkan } \\
\text { oleh ibu yang masih terlalu } \\
\text { muda namun mempunyai } \\
\text { riwayat kehamilan yang } \\
\text { sering. Akibatnya bayi juga } \\
\text { mengalami gangguan kognitif } \\
\text { yang perlu mendapat } \\
\text { perhatian. }\end{array}$ & 0 & $\begin{array}{l}\text { Terdapat } 10 \text { bayi stunting yang } \\
\text { dilahirkan oleh calon ibu dengan } \\
\text { usia sangat muda dan telah sering } \\
\text { melahirkan. Walau dapat } \\
\text { memberikan ASI, namun } \\
\text { kualitasnya sangat menurun } \\
\text { sehingga bayi mengalami } \\
\text { gangguan motorik, kognitif dan } \\
\text { verbal }\end{array}$ \\
\hline
\end{tabular}

Berdasarkan Tabel 5, terdapat kesamaan jumlah anggota cluster pada $\mathrm{k}=0$ untuk SSE dan $\mathrm{k}=1$ untuk DBI. Namun informasi yang dihasilkan berbeda. Perbedaan terletak pada atribut yang memiliki jarak lebih dekat pada pengujian dengan DBI. Setiap atribut saling terkait erat membentuk informasi dengan lengkap. Kedekatan jarak intra cluster ini menjadikan kinerja $D B I$ lebih baik, tidak hanya dalam penentuan jumlah cluster yang optimal, namun juga dalam menghasilkan informasi yang lebih rinci dan terpola.

\section{KESIMPULAN}

Teknik evaluasi cluster SSE dan DBI mampu menentukan jumlah cluster yang paling optimal dari serangkaian k yang diujikan pada data uji. Berdasarkan hasil pengujian, $S S E$ dan $D B I$ membentuk jumlah cluster optimal pada $\mathrm{k}=5$. Namun performa $D B I$ lebih baik dalam meminimalkan jarak intra cluster sehingga informasi yang terbentuk lebih lengkap dan terpola. Penelitian ini berbeda karena komparasi disertai dengan analisa hasil setiap $\mathrm{k}$ yang diujikan. Komparasi performa kedua teknik masih dapat dikembangkan melalui sejumlah data uji yang dibedakan dari segi jumlah maupun penggunaan pengukuran jarak dalam algoritma K-Means. Hasil penelitian ini diharapkan dapat memberikan pandangan baru dalam penggunaan teknik evaluasi cluster sehingga mempermudah pengguna untuk menentukan teknik yang sesuai dengan data yang ada dalam menghasilkan jumlah cluster yang paling optimal dan informasi yang benar.

\section{DAFTAR PUSTAKA}

[1] Sugiyamta, "Sistem Deteksi Kemiripan Dokumen Dengan Algoritma Cosine Similarity dan Single Pass Clustering," Din. Inform., vol. 7, no. 2, pp. 85-91, 2015.

[2] M. A. Syakur, B. K. Khotimah, E. M. S. Rochman, and B. D. Satoto, "Integration K-Means 
Clustering Method and Elbow Method for Identification of the Best Customer Profile Cluster," in IOP Conference Series: Materials Science and Engineering, 2017, vol. 336, no. 1, p. 7.

[3] P. Bholowalia and A. Kumar, "EBK-Means: A Clustering Technique based on Elbow Method and K-Means in WSN," Int. J. Comput. Appl., vol. 105, no. 9, pp. 17-24, 2014.

[4] Y. Zhang, T. Bouadi, and A. Martin, "An empirical study to determine the optimal k in EkNNclus method," in 5th International Conference on Beleif Functions (BELIEF2018), 2018, vol. 9, pp. 260-268.

[5] Widiarina, "Algoritma Cluster Dinamik Untuk Optimasi Cluster Pada Algoritma K-Means Dalam Pemetaan Nasabah Potensial," J. Intell. Syst., vol. 1, no. 1, pp. 33-36, 2015.

[6] I. D. Apriliyaningsih and D. Istiawan, "Penerapan Seleksi Atribut Berdasarkan Koefisien Variansi dan Korelasi untuk Inisialisasi Pusat Awal Klaster pada Algoritma K- Means dalam Pemetaan E-Government Tahun 2016," in Jurnal University Research Colloquium 2017 Universitas Muhammadiyah Magelang, 2017, no. September, pp. 245-250.

[7] M. Toumi, A. Maizate, M. Ouzzif, and M. S. Salah, "Dynamic clustering algorithm for tracking target with high and variable celerity (ATHVC)," J. Comput. Networks Commun., no. 10, pp. 475-480, 2016.

[8] N. P. E. Merliana, Ernawati, and A. J. Santoso, "Analisa Penentuan Jumlah Cluster Terbaik Pada Metode K-Means Clustering," in Prosiding Seminar Nasional Multi Disiplin Ilmu\&Call for Papers Unisbank (Sendi_U), 2015, pp. 978-979.

[9] H. P. Duvvada, G. D. R. Naidu, and V. D. Sri, "K-Means Cluster Analysis Of Cities Based On Their," Int. J. Eng. Dev. Res., vol. 5, no. 4, pp. 1356-1363, 2017.

[10] Irwanto, Y. Purwananto, and R. Soelaiman, "Optimasi Kinerja Algoritma Klasterisasi KMeans untuk Kuantisasi Warna Citra," J. Tek. ITS, vol. 1, no. 1, pp. A197-A202, 2012.

[11] P. Fränti, "Introduction," in Cluster Validation, 2017.

[12] Kementrian Kesehatan RI, "Situasi Balita Pendek (stunting) di Indonesia," Kementerian Kesehatan RI, vol. 1, pp. 1-43, 2018. 